\title{
It takes two: A dyadic model of recruitment to civic activity
}

\author{
Kraig Beyerlein ${ }^{a}{ }^{*}$, Kelly Bergstrand ${ }^{b}$ \\ a Department of Sociology, University of Notre Dame, United States \\ ${ }^{\mathrm{b}}$ Department of Sociology, University of Texas at Arlington, United States
}

\section{A R T I C L E I N F O}

\section{Article history:}

Received 30 November 2015

Received in revised form 23 June 2016

Accepted 27 July 2016

Available online xxx

\section{Keywords:}

Differential recruitment

Social networks

Civic engagement

Dyads

\begin{abstract}
A B S T R A C T
Why are some people, but not others, asked to engage in civic activity? Rather than focus on the personal traits of either potential recruits or recruiters for this initial stage of recruitment, we develop and test a theoretical framework that emphasizes the importance of shared relationships and characteristics between those doing the recruiting and those being recruited. Specifically, the nature of interactions, overlapping community and associational space, status and value homophily, and strength and intimacy are assessed to explain differential recruitment among people's closest ties. Furthermore, unlike previous studies, we do so across three different forms of civic activity-blood donation, volunteer work, and political activism-allowing us to identify larger patterns in civic solicitation. Results from multilevel analyses of dyads reorganized from ego-centric data of U.S. adults show that while certain personal traits of egos and alters remain significant, attributes of the dyad are equally, if not more, consequential for explaining variation in who gets asked to participate in civic activity. Importantly, while certain dyadic characteristics-such as romantic partnerships-promote recruitment to all three forms of civic activity, the effects of others-such as sex homophily-are unique to specific forms. Broadly speaking, our results indicate that some types of dyadic characteristics are more powerful than others and that there are important differences in how particular dimensions of social connections shape recruitment efforts across the specific activities of donating blood, volunteering time, and engaging in political activism.
\end{abstract}

(C) 2016 Elsevier Inc. All rights reserved.

Understanding why certain people but not others donate blood, volunteer time, and take political action has long been of interest to scholars of various disciplines. Although these activities constitute different forms of civic engagement, they share a common explanation. Across different fields, existing research consistently finds that "being asked" is among the strongest predictors. Blood donors most frequently cite influence from a friend as motivating first-time donation (Sojka and Sojka, 2008), while non-donors rank never receiving an invitation as the primary reason for not giving (Drake et al., 1982). Concerning volunteerism, a request to get involved nearly doubles the odds that people will help others (Musick et al., 2000). Furthermore, studies observe that being solicited substantially increases the probability of participating in political activism

\footnotetext{
For helpful comments on previous drafts, we thank participants in the Studies in Politics and Movements workshop at the University of Notre Dame. Laura Hunter provided excellent guidance on statistical modeling issues. A grant from the Science of Generosity supported the collection of data used in this paper. Direct correspondence to the first author at the Department of Sociology, 817 Flanner Hall, University of Notre Dame, Notre Dame, IN, 46556 (email: kbeyer11@nd.edu).

* Corresponding author.

E-mail address: kbeyerl1@nd.edu (K. Beyerlein).
} 
(Brady et al., 1999; Schussman and Soule, 2005; Verba et al., 1995). Simply put, recruitment matters-and in a big way-for distinguishing the civically engaged from the non-engaged.

But not everyone is equally likely to be targeted for civic activity. What explains why some people are recruited while others are not? ${ }^{1}$ Brady et al.'s (1999) "rational prospector" model offers an answer. It conceives of recruiters as utility maximizers who seek to solicit people with high participation potential-those who are expected to be valuable contributors once active. According to this perspective, people who possess the "right" traits-for instance high levels of education or leadership skills-are coveted and thus most susceptible to being asked to get involved in civic life (see also Bryant et al., 2003; Musick et al., 2000; Schussman and Soule, 2005).

While not denying the importance of receivers' personal characteristics for explaining variation in requests to participate in civic activity, recruitment involves two actors: the recruit and recruiter. Given its dyadic quality, a thorough understanding of differential recruitment requires attention to how these actors are connected. Relatively few studies, however, have focused on relational factors to explain why some people but not others are solicited for civic activity.

Walgrave and Wouters (2014) investigated the effect of tie strength on whether protesters received a participation request. Among a very large sample of protesters, they found that romantic partners, family members, or friends received more solicitations to get involved in demonstrations than did colleagues, co-members of organizations, or acquaintances. The significance of the strong-weak tie distinction has also been evaluated in the second stage of civic recruitment- "getting to the yes" among those who have been asked to participate. Relative to strangers, Brady et al. (1999) observed that people were more likely to assent to a request to get involved in political activity if it came from one of the following three sources: (1) a personal friend or relative; (2) an acquaintance; or (3) a job supervisor. By contrast, Lim (2008) identified no differences in positive responses to civic recruitment attempts between close friends/relatives and acquaintances, but he did observe that solicitations from strangers or indirect ties were less likely to be accepted than were those from acquaintances. Additionally, Lim (2008) found that people were more likely to "say yes" to a protest request if it came from a fellow civic association member, while a solicitation from a neighbor was more important for agreeing to participate in community politics. Finally, Brady et al. (1999) showed that racial and sex similarity tended to increase the probability of accepting appeals to take political action.

In this paper, we draw on but extend these studies to provide new insight into the factors that shape the initial stage of civic recruitment. Understanding why certain people but not others are asked in the first place is essential to understanding the pool of people selected to gain entry, or not, into the civic world. First, we examine differential recruitment across three different forms of civic engagement-blood donation, volunteerism, and political activism. To date, extant studies on solicitation focus exclusively on one form of activity, with political participation receiving the most attention. Second, we argue that whether a recruitment attempt occurs between two people is not simply due to the personal traits of either party, but is also a function of the types of relations, characteristics, and interactions they share. We study this in a more comprehensive way than previous studies by considering four distinct dimensions along which relations may vary: 1) frequency and type of interaction; 2) shared community and institutional space; 3) status and value homophily; and 4) strength and intimacy. A final contribution is that instead of analyzing solicitation differences between broad categories of strong and weak ties (e.g., friends versus acquaintances), we examine variation specifically in close ties. This allows us to assess differential recruitment effects that emerge from gradations in close relationships, providing a more nuanced look at how solicitation works among people's most influential connections.

Drawing on the scholarship on social networks, civic engagement, and social movements, we develop theoretical arguments that specify whether a particular type of tie is expected to have similar or different effects across the three forms of civic activity to gain a richer understanding of why invitations to participate in civic life are made (or not made) between two people who are close. Key to this issue is unpacking how differences in blood donation, volunteerism, and political activism make certain types of connections, such as neighborhood or homophilous ties, more or less salient for recruitment to one of these activities.

We test the theoretical expectations that follow by analyzing network data from of an ego-centric ("five people to whom you feel the closest") module from a recent nationally representative survey of the U.S. adult population that includes both civically active and non-active individuals. These data were restructured into alter-ego pairs to create a dyadic-recruitment measure as well as variables for other relational characteristics for these pairs. Because they were the survey respondents, we had access to a great deal of personal information about egos (the potential recruits). We are also able to include a measure for whether alters (potential recruiters) were civically engaged or not, which is an important control for the prospective asker (Walgrave and Wouters, 2014). Taken together, these features allowed us to construct a unique dataset in which dyadic-level characteristics and individual-level factors of recruitment could simultaneously be analyzed.

The dyadic nature of our analysis sets us apart from other studies on this first stage of recruitment: who gets asked or not to engage in civic activity. Not only do we have personal data, but we also have data on shared characteristics and connections between the person doing the recruiting and the potential recruit. We thus test not just whether, for example, people's personal embeddedness in voluntary associations leads to an invitation for civic activity, but also whether sharing organizational space with alters does. And, as an important comparison group, our data includes non-recruiters and non-recruits

\footnotetext{
1 See Snow et al. (1980) for an early conceptualization of differential recruitment as it pertains to joining social movement organizations.
} 
who may share connections that never lead to solicitations for civic activity. This allows us to identify the types of shared characteristics, interests, and spaces that are most central to recruitment among close ties.

\section{Social connections and differential recruitment: What types matter most and why?}

The nature of people's connections greatly varies. For instance, some individuals are bonded by blood, while shared beliefs link others. From the social network literature, we know that the significance of a particular type of relationship generally depends on what is at stake. As far as explaining differential recruitment to civic activity goes, we argue that the following four types of connections among close ties will be paramount: frequency and content of interaction, shared community and voluntary organizational space, status and value homophily, and strength and intimacy. Some of these relational characteristics are expected to have general effects that are applicable to recruitment across all three forms of civic activity. At the same time, differences in blood donation, volunteer work, and political activism should render certain types of ties more significant for recruitment into a specific activity.

\subsection{Frequency and content of interaction}

The first dyadic characteristic posited to affect whether close ties recruit each other to civic activity is frequency of interaction. The reason for this is simple. The more contact between people, the more opportunities there are to make requests to get involved. Other things being equal, then, we expect a greater probability of recruitment for close ties who see each other more often relative to those who see each other less often.

As far as being solicited for civic activity goes, not all interactions should equally lead to an invitation. Certain types of interactions may be particularly prone to providing openings for asking others to participate. Conversations about social and political matters are one such interaction, as they are likely to ease the transition to recruitment. Klofstad (2007) found that talking about politics and current events increases civic participation primarily because it is during these conversations that people are recruited. Unlike generic interaction, the importance of discussing social and political issues for recruitment should vary depending on the form of civic activity. Given the overlap in content, close ties who talk about politics should be especially susceptible to asking each other to participate in political activism. Discussions about social and political issues may also increase the probability of a request to do volunteer work since this form of civic activity tends to deal with social problems, many of which have political connotations, such as Parent-Teacher-Association members spending time working for school changes. Blood giving tends to be apolitical in nature, so these discussions should have little to no effect on recruiting others to donate.

Interaction and Recruitment Hypotheses:

H1. Close ties who interact more frequently with each other will have increased recruitment attempts across all three forms of civic activity.

H2. Close ties who discuss social and political issues with each other will have increased recruitment attempts in volunteer work and especially political activism.

\subsection{Shared space}

Not all close ties have the same opportunities to spend time together. Geographic propinquity is an important factor determining how often they can see each other. Because chances of interaction are greater when close ties live near each other, there should be more recruitment attempts for civic activity when these ties are fellow community members. People who are spatially proximate also have access to the same associations, clubs, congregations, and groups. This is significant as voluntary organizations are important social settings that bring people together to socialize (for example, see Feld, 1981). Furthermore, these organizations can cultivate discussions about social and political issues (Verba et al., 1995). Thus, people embedded in religious congregations and other associations of civil society may be exposed to more conversations and opportunities that open the door for recruitment. Similarly, political conversations occur across fences and at mailboxes (Huckfeldt and Sprague, 1995). Neighbors then, too, may find increased openings for civic recruitment during their interactions. For these reasons, we would expect close ties who are embedded in the same voluntary organization or community to solicit each other for civic activity at higher rates than those who do not have these settings in common.

Close ties who share neighborhood and institutional space also have other advantages when it comes to civic recruitment. People should be more likely to recruit others to donate blood, volunteer time, and take political action when these activities are accessible and convenient. A good amount of civic actions are locally focused (Sampson et al., 2005), such as neighborhood groups cleaning up parks or community-run blood drives. Indeed, Lim (2008) found that neighborhood ties have a positive effect on engaging in local political activity, such as working on community issues or problems. In addition, voluntary organizations are key infrastructures mobilizing civic participation, as they sponsor a variety of social service programs and provide space for activist projects. Given the many opportunities that communities and voluntary associations offer to become civically engaged, the likelihood of requests to get involved should be higher among close ties who share these contexts. 
Without a common cause around which to rally, however, opportunities are unlikely to materialize into recruitment attempts. Even if there are volunteer efforts that two friends can easily join-say, a pro-life demonstration run by their religious congregation-unless these efforts focus on issues that are of interest to both, the likelihood of them asking each other to participate should be low. From public safety to property zoning, communities have no shortage of causes that directly bear on residents' lives and well-being, making it easy to recruit for shared concerns. Concerning voluntary associations, they tend to attract people who share traits, like similarities in age, gender, education, and occupational status (McPherson and Smith-Lovin, 1987). These comparable traits serve as a platform for mutual interest in particular civic activities. Additionally, voluntary associations tend to be organized around a focal topic, like sports or helping children, which brings together people already interested in particular issues, creating an environment ripe for recruitment.

Furthermore, joint organizational and community membership can cultivate shared identities. Groups can be important in sustaining an identity and creating social incentives to participate in causes that reinforce that identity (McAdam and Paulsen, 1993). For example, people who participate together in a voluntary association focused on schooling issues are likely to develop more salient identities as educational advocates given exposure to information and leaders who are passionate about these issues. In turn, this could increase the likelihood that members recruit each other to participate in education-related activities. Through events such as neighborhood parades, recreational programs at city parks, or celebrations at local restaurants, communities strengthen people's attachment to the places they live. Combined with the opportunities that communities and voluntary associations provide for civic engagement, common causes and shared identities should give close ties who live in the same community or belong to the same voluntary group a significant edge when it comes to recruitment for civic activity.

Shared Space and Recruitment Hypotheses:

H3. Close ties who live in the same community will have increased recruitment attempts in all three forms of civic activity.

H4. Close ties who are members of the same voluntary organizations will have increased recruitment attempts in all three forms of civic activity.

\subsection{Homophily}

Whether people are demographically and ideologically matched should also be a factor explaining whether close ties ask each other to participate in civic activity. With homophily, "similarity breeds connection" (McPherson et al., 2001:415). In other words, people gravitate toward and forge ties with similar others. Sociodemographic traits such as sex, race, or age are one important dimension around which people cluster and bond. This sorting process reflects status homophily (Lazarsfeld and Merton, 1954; McPherson et al., 2001). In general, we expect close ties matched on status characteristics to be more likely to solicit each other for civic activity than those unmatched on them (c.f. Brady et al., 1999).

In the world of volunteerism and political activism, causes and types of work can be stratified along sociodemographic lines. Social movements may have gendered or racial divisions of labor. McAdam (1992) found that gender moderated both recruitment to and experiences during the Mississippi Freedom Summer Project; for instance, women tended to be directed toward clerical work and teaching while men were utilized more for direct action campaigns. Additionally, some protest activities are gender specific, such as men burning draft cards in Anti-Vietnam War demonstrations or women using the role of "mother" to mobilize for the disappearance of family members under military regimes (Kuumba, 2001). Other political activities are adopted by particular age groups, such as student movements, like the shantytowns tactics that emerged on college campuses to protest apartheid (Soule, 1997). To the extent that political activities are tailored to demographic subgroups, recruiters may seek similar close ties since they are viewed as being a good fit.

Also, shared demographic traits may signal whether close ties are interested in particular causes or types of activities. Women are more likely than are men to volunteer for caring, person-to-person work (Wilson, 2000) and constitute a larger share of some social movements, such as animal rights activism (Einwohner, 1999). Several surveys have found that women are more likely to volunteer in the domains of human services, health, education, and religion while men are more likely to volunteer for sports organizations and emergency services (Musick and Wilson, 2008). Gendered differences in civic arenas could lead to increased recruitment between sex-homophilous ties. Similarly, ethnic mobilization, which centers on a feature of ethnic identity, such as skin color, language, or customs (Olzak, 1983), could increase recruitment between close ties who are racially or ethnically homophilous. For instance, blacks are more likely to participate in cultural or ethnic organizations than are whites (Stoll, 2001), while Latinos represented the vast majority of marchers in the 2006 immigrant rights rallies (Pallares and Flores-González, 2010).

Blood donation differs from volunteer work and political activism in that it is more narrowly constructed around a single type of activity and cause-ensuring a safe and reliable blood supply to help save people's lives. Thus, because blood donation lacks variation in topics and activities, it should provide less incentive for people to recruit demographically-similar close ties into specific causes or tactics. This, in turn, is likely to decrease the importance of status homophily for recruitment into blood donation relative to the other forms of civic activity.

Dyads are homophilous in other ways that may affect differential recruitment. Value homophily pertains to similarities in values and belief systems (Lazarsfeld and Merton, 1954; McPherson et al., 2001). We expect that shared political views will go a long way in explaining variation in whether a recruitment attempt is made between two people who are close. Knoke (1990) 
posits that political homogeneity between ego and alters can mutually influence political attitudes and behaviors. This seems particularly significant for solicitations into activism-the most political of the three civic forms. We would not expect one close tie to ask another to participate in, say, canvassing efforts or rallies if she is ideologically opposed to them, making political concordance an important element in activist recruitment. Interest in certain types of volunteer work, too, may be conditioned by political similarities or agreement on social issues. Blood donation, on the other hand, is relatively free of political implications, rendering ideological agreement less important for recruiting.

Homophily and Recruitment Hypotheses:

H5. Homophily will increase recruitment attempts across all three forms of civic activity.

H6. Status homophily will matter more for both recruitment to volunteer work and political activism than for blood donation.

H7. Value homophily will matter most for recruitment to political activism, second most for volunteer work, and least for blood donation.

\subsection{Strength}

People generally care about what close ties think about them and want to maintain the quality of these connections. Thus, when these ties make a recruitment attempt, they are not only considering the benefits the potential participant can bring to the cause or civic activity at stake, but also how the act of asking will affect this significant personal relationship. But not all close ties are the same. They vary in terms of intimacy as well as emotional support and the type of relation, for example parent or child (Wellman, 1979, 1992). We posit that these gradations in tie strength will influence whether close ties recruit each other to civic activity.

Among those solicited, Brady et al. (1999) suggest that recruiters seek to use social leverage to dole out punishments and rewards in strategic and instrumental ways to "close the deal." Since there might be greater expectations and obligations to recruiters who are strong ties, individuals may be subject to more social pressure to agree to participate if asked by them (Paik and Navarre-Jackson, 2011). Given this, we expect recruitment attempts to occur more often between close ties who have a particularly strong connection (c.f. Walgrave and Wouters, 2014).

However, there are other considerations that close ties take into account when making recruitment attempts. Gould (2003) posits that one factor affecting recruitment into activism is that it can add value to friendships, potentially endowing them with special significance since activism tends to invoke sacrifices. If two friends participate in activism they can share in its personal transformations and experiences, while if only one participates, the friendship could be weakened as one person adopts different values and identities from the other and potentially forges new connections with other activists. Thus, recruitment into activism can provide "the benefit of enhancing a social relationship that is already valuable to both" (Gould, 2003:253). Similarly, elements of political activism can be enjoyable, potentially including enriching and exciting activities (Jasper, 1997), which could contribute to a desire to recruit, and be recruited by, people seeking to strengthen close relationships. Individuals who are strongly connected to each other are likely to have the ability to make dual participation in activities more attractive (McAdam, 1986). Thus, both social leverage, as well as concerns about maintaining or improving highly-valued social relationships and sharing fun and rewarding experiences, should render close ties with a particularly strong connection more susceptible to recruitment attempts than less strong close ties.

What are the different dimensions of tie strength? Among close ties, intimate ones generally provide greater support (Wellman, 1992). Close ties can also differ in the nature of the relationship, such as friends or kin. Spouses may be a particularly powerful source of social influence when it comes to recruitment attempts. Rotolo and Wilson (2006) find that spouses exert a positive influence in volunteer behavior; while 30\% of married men and $38 \%$ of married women volunteer, these rates substantially increase to $58 \%$ and $75 \%$, respectively, when the other spouse volunteers. Another important familial tie is the parent-child relationship, which can be an important source of social support and assistance (Wellman, 1979, 1992). Parents who volunteer frequently have children who volunteer as well; for instance, people with parents who both volunteered were almost three times more likely to volunteer compared to those with neither parent involved in volunteer work (Musick and Wilson, 2008).

Overall, close ties that are stronger in nature, such as spouses or other romantic partners, are expected to encourage recruitment to all three forms of civic activity, but we also predict that these ties will have varying degrees of significance depending on the specific form of activity. Because it is often intense in nature, individuals may be reluctant to engage in political activism on their own. Recruiting spouses or best friends to participate would thus help reduce fears and concerns. Similarly, volunteer work, especially when directed toward vulnerable populations, often deals with difficult or emotionallyladen situations that make more supportive network ties an attractive recruitment choice. On the other hand, both volunteer work and political activism can provide new and interesting experiences and opportunities for personal development. Thus, in both volunteer work and political activism, perceptions that co-participating in activities can make the experience more enjoyable, or less daunting, provide an incentive to recruit the strongest of one's close relations. In fact, some charitable groups actively encourage married couples to volunteer together, potentially tapping into desires for spouses to spend time with each other outside the household and helping to overcome uncertainties about volunteering (Rotolo and Wilson, 2006). 
Even if strong ties do not directly participate in volunteer and political efforts together, recruiting could be appealing simply by providing a common identity or topic of conversation.

Conversely, we hypothesize that blood donation is less susceptible to recruitment from stronger close ties given that it is relatively low in risk (though there is the fear of needles and physical fatigue) and generally does not involve difficult emotional situations. Plus, relative to volunteer work and political activism, blood donation is limited in its ability to offer an activity that people can participate in together and is less controversial. Moreover, the additional social pressure that stronger close ties can bring to bear on relations may be particularly important for recruiting to the relatively costly and potentially risky duties involved in volunteerism or political activism. Thus, we expect that strength-such as romantic connections-will increase civic recruitment overall, but that the magnitude of its effect will be largest for volunteer work and political activism.

Strength and Recruitment Hypotheses:

H8. Stronger relationships between close ties will increase the likelihood of recruitment attempts in all three forms of civic activity.

H9. Stronger relationships between close ties will have a greater positive effect on recruitment attempts for volunteer work and political activism than for blood donation.

\section{Data, measures, and methods}

\subsection{Data}

The above hypotheses about differential recruitment are tested using the 2010 Science of Generosity Survey (SGS). This web-based survey collected, among other things, information about various charitable activities and attitudes about them from a nationally representative sample of nearly 2000 U.S. adults aged 23 years and older in the summer of 2010. SGS's sample was drawn from Knowledge Networks' (KN) Knowledge Panel (KP). KP is a probability-based online panel containing respondents 18 years or older from over 50,000 households from all 50 states and the District of Columbia. KP panelists are recruited through a combination of random-digit-dial (RDD) and address-based-sampling (ABS) methods that generate a sampling frame covering approximately 97\% of all households in the United States (for more information, see Dennis, 2010). This panel is increasingly being used to collect data for social science projects, including recent waves of the American National Election Studies (ANES). Research has shown that the KP is representative of the United States as a whole and that the data collected from it are highly accurate (Callegaro and Disogra, 2008; Chang and Krosnick, 2009).

For the SGS, 3072 KP panelists were invited to participate. Of those, 1997 completed it for a completion rate (COMR) of $65 \% .^{2}$ A post-stratification weight was created to correct for several known demographic differences between the SGS sample and Current Population Study (CPS) benchmarks due to issues related to non-response. ${ }^{3}$

SGS's ego-network module is the focus of our paper. People were asked how many adults they "felt close to"-such as a spouse or romantic partner, adult family members, friends, neighbors, or people involved in the same group or organization -in the last 12 months. They could nominate up to five adults to whom they felt the closest and then were asked a series of questions about each one. The majority of SGS participants (60\%) nominated five adult close ties and respondents without any close ties (7\%) were excluded from the analysis because the focus is on how different characteristics of close ties affect differential recruitment and isolates lack data on these characteristics. The original egocentric network data were reorganized into distinct alter-ego pairs, resulting in a total of 7721 dyads. With this reorganization, we could examine the extent to which dyadic-level characteristics-such as whether egos and alters were the same sex, race, or age-explain variation in recruitment, above and beyond personal traits of prospective recruits.

Theoretically, ego could recruit alter to civic activity and vice versa. The models that follow, however, focus on alters' recruitment of egos. This decision was made so that potential recruits' personal traits, the focus of prior research on differential recruitment (Brady et al., 1999; Bryant et al., 2003; Musick and Wilson, 2008; Musick et al., 2000; Schussman and Soule, 2005), could be adequately operationalized and evaluated against our dyadic perspective (shared traits between prospective recruiters and recruits).

\footnotetext{
${ }^{2}$ Calculated based on Callegaro and DiSorga's (2008) formula. In addition to reporting the COMR, these scholars recommend that researchers using probability-based Internet panels report the recruitment rate (RECR), the profile rate (PROR), and the final cumulative response rate (CUMRR1). For the SGS, the RECR $=0.182$; the PROR $=0.554$; and the CUMRR $1=0.066$, which is comparable to that of the American National Election Studies (ANES). Although this response rate likely seems low in RDD standards, comparing the response rates of probability-based Internet surveys to those of RDD surveys is not advisable since they are substantively different (Callegaro and Disogra, 2008 3341). Additionally, response rates in themselves do not indicate the severity (or lack thereof) of non-response bias (Groves, 2006 3344; Groves and Peytcheva, 2008 3345), nor do higher ones necessarily indicate greater accuracy of response (Yeager et al., 2011 3343).

${ }^{3}$ The variables that comprise the SGS-specific post-stratification weight are age, race/ethnicity, education, marital status, geographic region, metropolitan area, home internet access, and volunteer status. Weight trimming was $1.0 \%$ and $99.0 \%$ and the overall design effect was 1.150 .
} 
Table 1

Descriptive statistics for variables used in analysis.

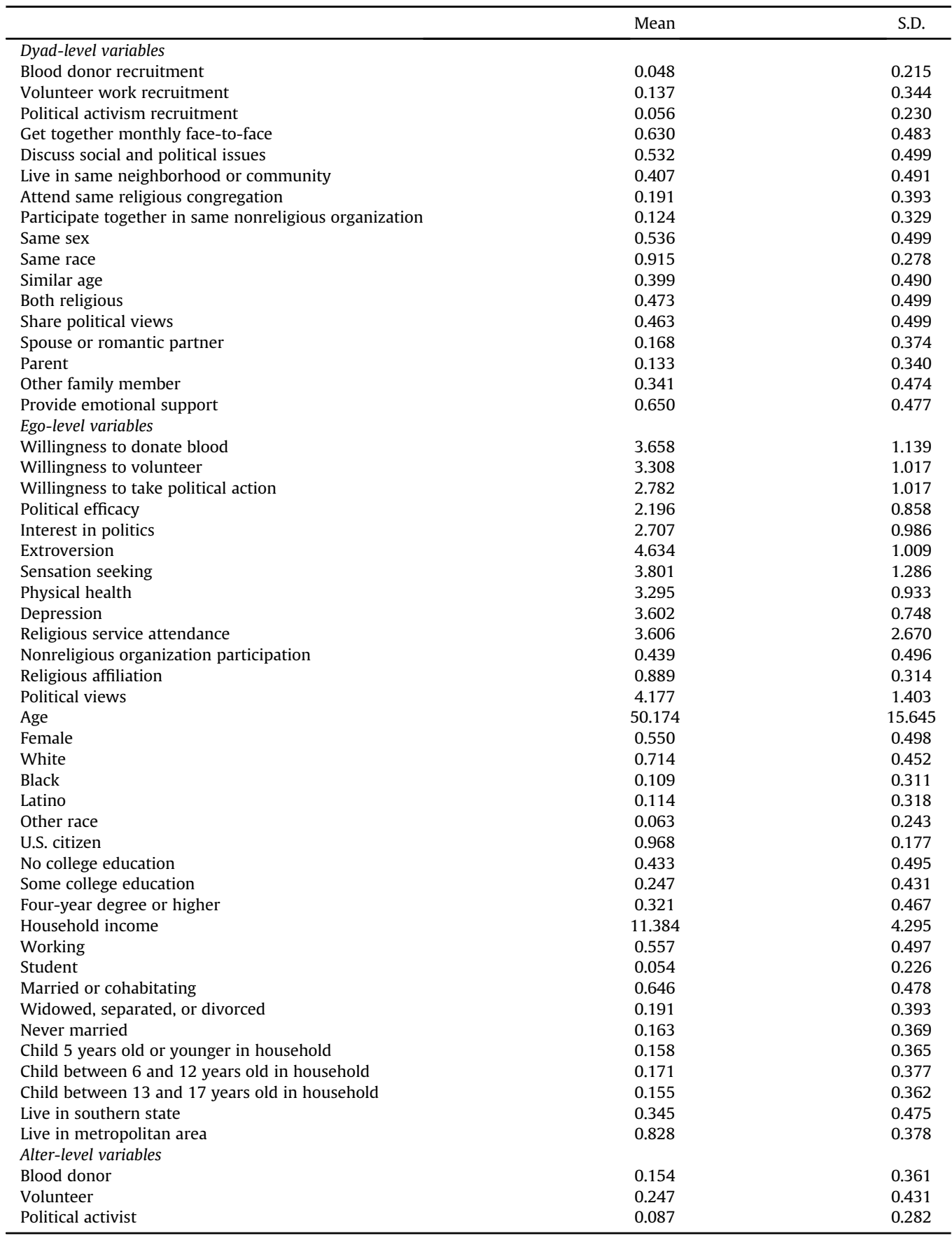

\subsection{Measures}

\subsubsection{Recruitment to donate blood, volunteer time, and take political action}

Respondents were asked whether or not in the last 12 months each nominated alter had recruited ("asked or encouraged") them to: 1) give blood; 2) do volunteer work for charitable causes; or 3) participate in political activism. Recruitment for each civic activity was analyzed separately. If alter asked ego to get involved, that particular dyad was coded as one to indicate alter-ego recruitment. When no such request was made, the dyad was assigned a value of zero. Looking at Table 1 , we see that, 
at $14 \%$, alters were most likely to ask their egos to volunteer to help others. Recruitment to donate blood or take political action was less common (5\% and 6\%, respectively).

\subsubsection{Dyadic-relational characteristics}

To evaluate our differential recruitment hypotheses about interaction, shared space, homophily, and strength, we measure the presence or absence of these connections between egos and alters in the last 12 months. For these measures, presence was coded as one and absence as zero. More frequent interaction was operationalized as ego-alter pairs that "got together in person once a month or more." Sixty-three percent of dyads in our sample interacted in this manner. Politically-oriented interactions should also matter for recruitment to civic activity, especially activism. Discussing social and political issues was used to measure these interactions. On average, more than half of close ties had conversations about politics during the past year.

Shared space was measured in two ways. One measure was whether egos and alters lived in the same neighborhood or community. Over $40 \%$ of dyads were fellow neighborhood or community members. Joint involvement in voluntary organizations was the second measure. Religious and non-religious associational connections were both assessed. In our sample, about a fifth of ego-alter pairs attended the same religious congregation, while they participated together in other groups or organizations somewhat less frequently (13\%).

Regarding homophily, we distinguish status and value forms. Four distinct status dimensions were measured: race/ ethnicity, sex, age, and religiosity. Over $90 \%$ of dyads were racially/ethnically homophilous. Slightly more than half of the egoalter pairs shared a sex and slightly less than half were both religious, while two out of every five were similar in age. For value homophily, a single measure was used for whether egos and alters "agreed about social and political issues." Forty-six percent of close ties were matched on political views.

The final dyadic characteristic included was tie strength. One measure of this characteristic was whether ego and alter were spouses or romantic partners. In our sample, $17 \%$ of close ties were connected in this way. Next, we captured whether alter was a parent or a person who raised ego. Thirteen percent of all dyads were parent-child relationships. Egos and alters could also be siblings, grandparents, cousins, aunts, uncles, and so on. At $34 \%$, this type of familial connection was most common in our sample. The final measure of tie strength was whether alters were "a source of emotional support" for ego, which was the case $65 \%$ of the time.

\subsubsection{Prospective recruits' personal traits}

Given prior research's focus on prospective recruits' personal traits to explain differential recruitment, our models included these traits for the survey respondent or ego. Separate 5-point ordinal willingness variables (ranging from extremely unwilling to extremely willing) for blood donation, volunteer work, and political activism were included to match the three different forms of civic activity in the recruitment models. Efficacy was also a 5-point ordinal variable for how much overall impact respondents thought they could have on community and political affairs (higher scores reflected more efficacious feelings). Ego's political interest was a four-point ordinal variable (ranging from not at all interested to very interested).

Scales were created for extroversion and a sensation-seeking disposition. Indicators such as "I am talkative" or "I am outgoing or sociable" were used to construct the former, while the later relied on "I like to explore strange places" or "I like new and exciting experiences, even if I have to break the rules," among others. All indicators were 7-point ordinal variables ranging from strongly disagree to strongly agree, so higher values indicated greater extroversion or sensation seeking. Both scales had a high alpha-reliability value ( 0.782 and 0.780 , respectively).

Mental and physical health measures were also included. We created a depression scale based on how often in the last 12 months egos had such experiences as "feeling sad or down" or "having trouble falling asleep or sleeping too much." Each experience was assessed with a five-point ordinal variable ranging from never to very often. This scale's alpha-reliability was 0.874. Self-reported physical health was measured with a 5-point ordinal variable, ranging from extremely poor to excellent.

Respondents' organizational involvement was assessed with two different variables. First, religious service attendance was a 7-point ordinal variable coded so that higher values reflected more frequent attendance. The second measure was a binary variable for active involvement in voluntary organizations other than congregations, such as veterans groups, neighborhood associations, or hobby clubs. A binary measure for whether respondents reported a religious affiliation was also included. Egos' political views were captured with a 5-point ordinal variable, ranging from extremely conservative to extremely liberal.

Demographic characteristics were the final set of individual-level factors for which we accounted. Age was a continuous variable for how old respondents were at the time of the survey. Sex was coded 1 for females and 0 for males. Race was measured with four mutually exclusive binary variables: white, black, Latino, and other (the reference category). U.S. citizens were coded as 1 and non-citizens as 0 . Three mutually exclusive binary variables for respondents' educational level were included: no college education (the reference group), some college education, and a bachelor's degree or more. Household income was a 19 -category variable, ranging from less than $\$ 5000$ to $\$ 175,000$ or more. Working status was a binary variable with those currently employed coded as 1 and the unemployed coded as 0 . Student status was also a binary variable $(1=$ student). Marital status was assessed with three mutually exclusive binary variables: married or cohabiting; separated, divorced, or widowed; and never married (the reference group). Separate dichotomous variables were included for whether egos were a parent of at least one child 5 or under, between 6 and 12 years old, and between 13 and 17 years old. Finally, two geographic variables were included. Living in a Southern state and being a resident of a metropolitan area (both dichotomously coded). 


\subsubsection{Alters' civic activity}

Almost all questions pertaining to alters referred to how they were connected to egos. The survey did, however, ask egos if each alter donated blood, volunteered time, or took political action in the past 12 months. This allowed us to include a binary variable for whether alters had participated in the civic activity of interest (coded as 1). Given Walgrave and Wouters' (2014) work on the significance of recruiters' motivation and capacity for explaining differences in solicitation, this constitutes an important alter-level control in our dyadic recruitment models.

\subsection{Methods}

The reorganized egocentric data from the SGS are multilevel in nature, as alters are nested in egos. Given this structure, we employed hierarchical models. Dyadic-network characteristics described above constitute the level 1 unit, while the level 2 unit is ego's personal information. ${ }^{4}$ Although they focus on different substantive topics, several studies have transformed egolevel network data into dyadic-level data and analyzed them in a multilevel framework (for example, see Luken and Tranmer, 2010; van Duijn et al., 1999). Because the outcome is dichotomous (whether alter recruited ego for civic activity or not), multilevel logistic regression models were used. The coefficients for level 1 (dyad) and level 2 (ego) are fixed effects. The random effect is the intercept of the regression model at level 2.

Missing information for variables in the SGS was very low. For the multilevel logistic models, we handled missing data (4\%) with listwise deletion. ${ }^{5}$ Doing so dropped the original number of dyad cases from 7721 to 7441 for blood donor recruitment, to 7412 for volunteer work recruitment, and to 7449 for political activism recruitment (the number of cases vary because of differences in missing information for the willingness variable unique to each outcome: 14,43 , and 11 cases were, respectively, missing for blood donor, volunteer work, and political activism willingness).

\section{Results}

\subsection{Prospective recruits' personal traits and recruitment to civic activity}

Reflecting the focus of prior scholarship to explain differential recruitment, the initial models in Tables $2-4$ only include prospective recruits' personal characteristics. Looking at the first row in Table 2, we see that the more willing egos are to donate blood, the more likely alters are to ask them to give. Of the two personality measures, extroversion has a significant positive effect on donor recruitment. Mental and physical health are also important predictors of blood donor solicitation. While alters are less likely to recruit egos who are more depressed, they are more likely to ask those who are in better physical shape. Concerning demographics, being older in age and female as well as more highly educated all reduce the likelihood of being invited to donate blood. ${ }^{6}$

Mirroring blood donation, the first model in Table 3 shows a significant positive relationship between egos' willingness to do volunteer work and being asked to do so. In addition, more politically efficacious respondents are more susceptible to a request to volunteer. Egos' involvement in civil society renders recruitment to help others more probable. Compared to respondents with no college education, those with some college education are more likely to be solicited to volunteer. Lastly, parents of teenage children have a significant positive effect on being targeted for volunteerism.

As with recruitment for the other two forms of civic activity, greater willingness to engage in political activism increases the likelihood of egos extending an invitation to be active in this civic form. Higher levels of political efficacy and interest in politics have similar effects. Respondents who are more active in religious congregations and other types of voluntary associations are also more likely to be solicited for political activism. Only one demographic characteristic differentiates political recruits from non-recruits. African Americans are more likely to be asked than are people of the omitted racial group.

\subsection{Dyadic characteristics and recruitment to civic activity}

The second models in Tables 2-4 introduce the four sets of dyadic measures-interaction, shared space, homophily, and strength-along with the important recruiter variable for whether alters were civically engaged or not. Compared to the model with only ego-level characteristics ( $\mathrm{AIC}=2792$; $\mathrm{BIC}=3006$ ), the introduction of alter-level characteristics significantly improves the fit $(\mathrm{AIC}=2263$; $\mathrm{BIC}=2581$ ). Beginning with solicitation to donate blood, we see that several dyadic-level factors further our understanding of this civic activity. Net of personal traits, alters are more likely to ask egos to give blood when they live in the same neighborhood or community. Sharing a religious organization also increases alter-ego requests for this civic activity. The odds of these requests are over 1.5 times when dyads attend the same congregation relative to when they do not

\footnotetext{
${ }^{4}$ Like others, we assume that there is no overlap between one ego's alters in our sample and another's (Luken and Tranmer, 2010). This seems like a reasonable assumption given that the data are nationally representative and focus on people's five closest ties.

${ }^{5}$ Regarding individual variables, ego's political views, at $1.4 \%$, had the highest rate of missingness.

${ }^{6}$ That higher levels of education have a negative effect on recruitment to blood donation may be surprising. According to the rational prospector model, however, people are recruiting those seen as having the right skills for the job, but blood donation does not require a particular skill set and so additional education is not expected to give any special boost for this civic activity. Indeed, those without a college degree might have increased recruitment if they are viewed as having fewer competing recruit attempts to other civic activities, increasing perceptions that they might say "yes" to the request.
} 
Table 2

Coefficients from multilevel logistic regression models predicting recruitment to donate blood.

\begin{tabular}{|c|c|c|}
\hline Predictor variables & Model 1 & Model 2 \\
\hline \multicolumn{3}{|l|}{ Ego-level } \\
\hline Willingness to donate blood & $\begin{array}{c}0.523^{* * * *} \\
(0.080)\end{array}$ & $\begin{array}{c}0.520^{* * * *} \\
(0.093)\end{array}$ \\
\hline Political efficacy & $\begin{array}{c}0.101 \\
(0.096)\end{array}$ & $\begin{array}{c}0.111 \\
(0.111)\end{array}$ \\
\hline Interest in politics & $\begin{array}{l}-0.002 \\
(0.093)\end{array}$ & $\begin{array}{l}-0.101 \\
(0.109)\end{array}$ \\
\hline Extroversion & $\begin{array}{l}0.202^{*} \\
(0.095)\end{array}$ & $\begin{array}{c}0.144 \\
(0.110)\end{array}$ \\
\hline Sensation seeking & $\begin{array}{c}0.128 \\
(0.071)\end{array}$ & $\begin{array}{c}0.086 \\
(0.082)\end{array}$ \\
\hline Physical health & $\begin{array}{c}0.373^{* * * *} \\
(0.104)\end{array}$ & $\begin{array}{c}0.465^{* * *} \\
(0.122)\end{array}$ \\
\hline Depression & $\begin{array}{c}-0.443^{* * *} \\
(0.122)\end{array}$ & $\begin{array}{c}-0.392^{* *} \\
(0.142)\end{array}$ \\
\hline Religious service attendance & $\begin{array}{c}0.047 \\
(0.035)\end{array}$ & $\begin{array}{l}-0.012 \\
(0.042)\end{array}$ \\
\hline Nonreligious organization participation & $\begin{array}{c}0.047 \\
(0.177)\end{array}$ & $\begin{array}{l}-0.164 \\
(0.206)\end{array}$ \\
\hline Religious affiliation & $\begin{array}{c}0.557 \\
(0.316)\end{array}$ & $\begin{array}{c}0.519 \\
(0.373)\end{array}$ \\
\hline Political views & $\begin{array}{c}0.020 \\
(0.061)\end{array}$ & $\begin{array}{c}0.018 \\
(0.070)\end{array}$ \\
\hline Age & $\begin{array}{c}-0.027^{* * *} \\
(0.007)\end{array}$ & $\begin{array}{c}-0.025^{* *} \\
(0.009)\end{array}$ \\
\hline Female & $\begin{array}{l}-0.432^{*} \\
(0.171)\end{array}$ & $\begin{array}{c}-0.479^{*} \\
(0.198)\end{array}$ \\
\hline White & $\begin{array}{l}-0.304 \\
(0.332)\end{array}$ & $\begin{array}{l}-0.544 \\
(0.381)\end{array}$ \\
\hline Black & $\begin{array}{c}0.466 \\
(0.403)\end{array}$ & $\begin{array}{c}0.465 \\
(0.463)\end{array}$ \\
\hline Latino & $\begin{array}{l}-0.129 \\
(0.397)\end{array}$ & $\begin{array}{l}-0.246 \\
(0.454)\end{array}$ \\
\hline U.S. citizen & $\begin{array}{l}-0.152 \\
(0.520)\end{array}$ & $\begin{array}{c}0.206 \\
(0.614)\end{array}$ \\
\hline Some college education & $\begin{array}{c}-0.623^{* *} \\
(0.209)\end{array}$ & $\begin{array}{c}-0.647^{* *} \\
(0.241)\end{array}$ \\
\hline Four-year degree or higher & $\begin{array}{c}-0.730^{* *} \\
(0.238)\end{array}$ & $\begin{array}{c}-0.742^{* *} \\
(0.273)\end{array}$ \\
\hline Household income & $\begin{array}{l}-0.027 \\
(0.023)\end{array}$ & $\begin{array}{l}-0.050 \\
(0.027)\end{array}$ \\
\hline Working & $\begin{array}{c}0.218 \\
(0.192)\end{array}$ & $\begin{array}{c}0.187 \\
(0.220)\end{array}$ \\
\hline Student & $\begin{array}{c}0.266 \\
(0.308)\end{array}$ & $\begin{array}{c}0.033 \\
(0.357)\end{array}$ \\
\hline Married or cohabitating & $\begin{array}{c}0.235 \\
(0.232)\end{array}$ & $\begin{array}{c}0.226 \\
(0.269)\end{array}$ \\
\hline Widowed, separated, or divorced & $\begin{array}{c}0.176 \\
(0.292)\end{array}$ & $\begin{array}{c}0.355 \\
(0.334)\end{array}$ \\
\hline Child 5 years old or younger in household & $\begin{array}{l}-0.369 \\
(0.261)\end{array}$ & $\begin{array}{l}-0.435 \\
(0.300)\end{array}$ \\
\hline Child between 6 and 12 years old in household & $\begin{array}{c}0.362 \\
(0.227)\end{array}$ & $\begin{array}{c}0.343 \\
(0.261)\end{array}$ \\
\hline Child between 13 and 17 years old in household & $\begin{array}{c}0.162 \\
(0.230)\end{array}$ & $\begin{array}{c}0.106 \\
(0.264)\end{array}$ \\
\hline Live in southern state & $\begin{array}{c}0.012 \\
(0.175)\end{array}$ & $\begin{array}{l}-0.165 \\
(0.202)\end{array}$ \\
\hline Live in metropolitan area & $\begin{array}{c}0.063 \\
(0.217)\end{array}$ & $\begin{array}{c}0.090 \\
(0.249)\end{array}$ \\
\hline Dyad-level & & \\
\hline Get together monthly face-to-face & & $\begin{array}{c}0.077 \\
(0.193)\end{array}$ \\
\hline Discuss social and political issues & & $\begin{array}{c}0.364 \\
(0.195)\end{array}$ \\
\hline Live in same neighborhood or community & & $\begin{array}{l}0.413^{*} \\
(0.172)\end{array}$ \\
\hline Attend same religious congregation & & $\begin{array}{l}0.440^{*} \\
(0.196)\end{array}$ \\
\hline Participate together same nonreligious organization & & $\begin{array}{c}0.300 \\
(0.200)\end{array}$ \\
\hline
\end{tabular}


Table 2 (continued)

\begin{tabular}{|c|c|c|}
\hline Predictor variables & Model 1 & Model 2 \\
\hline Same sex & & $\begin{array}{l}-0.020 \\
(0.172)\end{array}$ \\
\hline Same race & & $\begin{array}{c}-0.549^{*} \\
(0.256)\end{array}$ \\
\hline Similar age & & $\begin{array}{l}-0.091 \\
(0.174)\end{array}$ \\
\hline Both religious & & $\begin{array}{c}0.046 \\
(0.185)\end{array}$ \\
\hline Share political views & & $\begin{array}{c}0.265 \\
(0.182)\end{array}$ \\
\hline Spouse or romantic partner & & $\begin{array}{c}0.993^{* * * *} \\
(0.245)\end{array}$ \\
\hline Parent & & $\begin{array}{c}0.352 \\
(0.269)\end{array}$ \\
\hline Other family member & & $\begin{array}{c}0.303 \\
(0.212)\end{array}$ \\
\hline Provide emotional support & & $\begin{array}{c}0.175 \\
(0.189)\end{array}$ \\
\hline \multicolumn{3}{|l|}{ Alter-level } \\
\hline Blood donor & & $\begin{array}{c}3.038^{* * * *} \\
(0.177)\end{array}$ \\
\hline Constant & $\begin{array}{c}-6.002^{* * * *} \\
(0.998)\end{array}$ & $\begin{array}{c}-7.392^{* * * *} \\
(1.217)\end{array}$ \\
\hline AIC & 2791.732 & 2263.114 \\
\hline BIC & 3006.089 & 2581.193 \\
\hline Observations & 7441 & 7441 \\
\hline Number of groups & 1792 & 1792 \\
\hline
\end{tabular}

Note: Standard errors in parentheses.

${ }^{* * *} \mathrm{p}<0.001 ;{ }^{* *} \mathrm{p}<0.01 ;{ }^{*} \mathrm{p}<0.05$ (two-tailed tests).

(exp $[0.440]=1.553$ ). Only one significant effect for homophily was observed. Unexpectedly, racially-matched pairs were less likely to make a blood donation request. On the other hand, the odds of alters asking egos to give blood significantly increase for spouses or other romantic partners, making recruitment offers over 2.5 times more likely for these intimate ties (exp $[0.993]=2.699]$.

Contrary to blood-donor recruitment, how often dyads interact and the nature of their interaction affect requests to do volunteer work. Alters are more likely to invite egos to volunteer if they get together in person on a monthly basis. Political discussions also increase the probability of alter-ego volunteer solicitation. Joint participation in a congregation or another type of voluntary association also makes it more likely that an offer to help others is made. Regarding homophily, two of the five measures are significant. The odds of alters asking egos to do volunteer work are 1.3 times greater for same-sex dyads relative to those of different sexes $(\exp [0.267)=1.306)$. Close ties who are both religious also heighten volunteer recruitment. Tie strength also affects the likelihood of alters asking egos to volunteer. On the one hand, marriage or other romantic relations have significant positive effects, while familial ties that are not these relations or parental in nature significantly discourage recruitment to volunteerism. Also, unlike requests to donate blood, we see that having an emotional connection matters, rendering the odds of recruitment for volunteer work over 2 times more likely (exp [0.738] $=2.092$ ). The alter solicitation model shows a significant improvement in fit relative to the ego only one above (AIC $=5810$; $\mathrm{BIC}=6024$ compared to $\mathrm{AIC}=4365$; $\mathrm{BIC}=4682$ ).

Similar to volunteer requests, both frequent interaction and social and political discussions between alters and egos increase the likelihood of recruitment for political activism. Discussing social and political issues has a particularly strong effect on activist solicitations, with the odds being 3 times more likely ( $\exp [1.101]=3.007)$. Also, like invitations to volunteer, dyads matched on sex are more prone to requests to get involved in political action. For the first time, value homophily is significant. The odds of alters asking egos to participate in political activism are 1.6 times greater when these pairs share political views compared to when they do not (exp $[0.480]=1.616)$. Another first is that soliciting for political activism occurs more often in parent-child dyads. Consistent with blood donor and volunteer recruitment, marriage or other romantic connections are associated with higher rates of offers for political engagement. As was the case for blood donor and volunteer recruitment, we see that the inclusion of alter-level characteristics (AIC $=2160$; BIC $=2478$ ) significantly improves the fit relative to only including ego-level characteristics ( $\mathrm{AIC}=3354$; $\mathrm{BIC}=3569$ ).

Comparing the first and second set of models across the three multivariate tables, while the effects of certain personal traits of egos-most notably willingness to engage in civic activity-remain significant with the inclusion of the dyadic factors, others do not or take a substantial hit in magnitude. For volunteer recruitment, the effect of ego's religious service attendance falls to nonsignificance when alter-ego connections are added. Additionally, the size of the coefficient for respondent's membership in other types of voluntary associations drops by more than half between models 1 and 2. Regarding requests to take political action, the individual-level measure of political interest lost significance after the various dyadic 
Table 3

Coefficients from multilevel logistic regression models predicting recruitment to do volunteer work.

\begin{tabular}{|c|c|c|}
\hline Predictor variables & Model 1 & Model 2 \\
\hline \multicolumn{3}{|l|}{ Ego-level } \\
\hline Willingness to volunteer & $\begin{array}{c}0.484^{* * *} \\
(0.069)\end{array}$ & $\begin{array}{c}0.368^{* * *} \\
(0.082)\end{array}$ \\
\hline \multirow[t]{2}{*}{ Political efficacy } & $\begin{array}{l}0.217^{* *} \\
(0.074)\end{array}$ & 0.154 \\
\hline & & $(0.088)$ \\
\hline Interest in politics & $\begin{array}{c}0.018 \\
(0.068)\end{array}$ & $\begin{array}{l}-0.038 \\
(0.082)\end{array}$ \\
\hline Extroversion & $\begin{array}{c}0.087 \\
(0.067)\end{array}$ & $\begin{array}{c}0.040 \\
(0.079)\end{array}$ \\
\hline Sensation seeking & $\begin{array}{c}0.088 \\
(0.051)\end{array}$ & $\begin{array}{l}0.135^{*} \\
(0.061)\end{array}$ \\
\hline Physical health & $\begin{array}{l}-0.141 \\
(0.074)\end{array}$ & $\begin{array}{l}-0.131 \\
(0.088)\end{array}$ \\
\hline Depression & $\begin{array}{l}-0.029 \\
(0.091)\end{array}$ & $\begin{array}{l}-0.035 \\
(0.109)\end{array}$ \\
\hline Religious service attendance & $\begin{array}{c}0.135^{* * *} \\
(0.025)\end{array}$ & $\begin{array}{c}0.008 \\
(0.031)\end{array}$ \\
\hline Nonreligious organization participation & $\begin{array}{c}0.664^{* * *} \\
(0.127)\end{array}$ & $\begin{array}{l}0.298^{*} \\
(0.151)\end{array}$ \\
\hline Religious affiliation & $\begin{array}{c}0.087 \\
(0.212)\end{array}$ & $\begin{array}{c}0.083 \\
(0.252)\end{array}$ \\
\hline Political views & $\begin{array}{l}-0.012 \\
(0.044)\end{array}$ & $\begin{array}{l}-0.063 \\
(0.052)\end{array}$ \\
\hline Age & $\begin{array}{l}-0.003 \\
(0.005)\end{array}$ & $\begin{array}{l}-0.002 \\
(0.006)\end{array}$ \\
\hline Female & $\begin{array}{l}-0.221 \\
(0.123)\end{array}$ & $\begin{array}{l}-0.161 \\
(0.147)\end{array}$ \\
\hline White & $\begin{array}{l}-0.092 \\
(0.247)\end{array}$ & $\begin{array}{l}-0.294 \\
(0.292)\end{array}$ \\
\hline Black & $\begin{array}{c}0.224 \\
(0.306)\end{array}$ & $\begin{array}{c}0.312 \\
(0.360)\end{array}$ \\
\hline Latino & $\begin{array}{c}0.123 \\
(0.298)\end{array}$ & $\begin{array}{c}0.437 \\
(0.351)\end{array}$ \\
\hline U.S. citizen & $\begin{array}{l}-0.371 \\
(0.398)\end{array}$ & $\begin{array}{l}-0.145 \\
(0.478)\end{array}$ \\
\hline Some college education & $\begin{array}{l}0.309^{*} \\
(0.148)\end{array}$ & $\begin{array}{c}0.177 \\
(0.175)\end{array}$ \\
\hline Four-year degree or higher & $\begin{array}{l}-0.012 \\
(0.166)\end{array}$ & $\begin{array}{l}-0.268 \\
(0.197)\end{array}$ \\
\hline Household income & $\begin{array}{l}-0.004 \\
(0.017)\end{array}$ & $\begin{array}{l}-0.008 \\
(0.020)\end{array}$ \\
\hline Working & $\begin{array}{c}0.115 \\
(0.137)\end{array}$ & $\begin{array}{c}0.001 \\
(0.163)\end{array}$ \\
\hline Student & $\begin{array}{c}0.261 \\
(0.235)\end{array}$ & $\begin{array}{c}0.282 \\
(0.276)\end{array}$ \\
\hline Married or cohabitating & $\begin{array}{c}0.216 \\
(0.171)\end{array}$ & $\begin{array}{c}0.131 \\
(0.201)\end{array}$ \\
\hline Widowed, separated, or divorced & $\begin{array}{l}-0.017 \\
(0.208)\end{array}$ & $\begin{array}{l}-0.056 \\
(0.243)\end{array}$ \\
\hline Child 5 years old or younger in household & $\begin{array}{l}-0.078 \\
(0.196)\end{array}$ & $\begin{array}{c}0.077 \\
(0.232)\end{array}$ \\
\hline Child between 6 and 12 years old in household & $\begin{array}{l}-0.035 \\
(0.171)\end{array}$ & $\begin{array}{l}-0.204 \\
(0.202)\end{array}$ \\
\hline Child between 13 and 17 years old in household & $\begin{array}{l}0.454^{* *} \\
(0.168)\end{array}$ & $\begin{array}{l}0.474^{*} \\
(0.196)\end{array}$ \\
\hline Live in southern state & $\begin{array}{c}0.006 \\
(0.127)\end{array}$ & $\begin{array}{c}0.040 \\
(0.150)\end{array}$ \\
\hline Live in metropolitan area & $\begin{array}{c}0.219 \\
(0.154)\end{array}$ & $\begin{array}{l}0.383^{*} \\
(0.183)\end{array}$ \\
\hline Dyad-level & & \\
\hline Get together monthly face-to-face & & $\begin{array}{l}0.378^{* *} \\
(0.132)\end{array}$ \\
\hline Discuss social and political issues & & $\begin{array}{l}0.311^{*} \\
(0.133)\end{array}$ \\
\hline Live in same neighborhood or community & & $\begin{array}{c}0.206 \\
(0.117)\end{array}$ \\
\hline Attend same religious congregation & & $\begin{array}{c}0.622^{* * * *} \\
(0.138)\end{array}$ \\
\hline
\end{tabular}


Table 3 (continued)

\begin{tabular}{|c|c|c|}
\hline Predictor variables & Model 1 & Model 2 \\
\hline & & $\begin{array}{c}0.939^{* * *} \\
(0.134)\end{array}$ \\
\hline Same sex & & $\begin{array}{l}0.267^{*} \\
(0.119)\end{array}$ \\
\hline Same race & & $\begin{array}{c}0.091 \\
(0.199)\end{array}$ \\
\hline Similar age & & $\begin{array}{l}-0.077 \\
(0.120)\end{array}$ \\
\hline Both religious & & $\begin{array}{c}0.280^{*} \\
(0.127)\end{array}$ \\
\hline Share political views & & $\begin{array}{c}0.237 \\
(0.125)\end{array}$ \\
\hline Spouse or romantic partner & & $\begin{array}{l}0.480^{* * *} \\
(0.171)\end{array}$ \\
\hline Parent & & $\begin{array}{c}0.296 \\
(0.184)\end{array}$ \\
\hline Other family member & & $\begin{array}{c}-0.292^{*} \\
(0.142)\end{array}$ \\
\hline Provide emotional support & & $\begin{array}{c}0.738^{* * * *} \\
(0.135)\end{array}$ \\
\hline Alter-level & & \\
\hline Volunteer & & $\begin{array}{c}3.134^{* * *} \\
(0.134)\end{array}$ \\
\hline Constant & $\begin{array}{c}-5.468^{* * *} \\
(0.727)\end{array}$ & $\begin{array}{c}-7.391^{* * * *} \\
(0.902)\end{array}$ \\
\hline AIC & 5810.279 & 4364.506 \\
\hline BIC & 6024.513 & 4682.405 \\
\hline Observations & 7412 & 7412 \\
\hline Number of groups & 1786 & 1786 \\
\hline
\end{tabular}

Note: Standard errors in parentheses.

${ }^{* * *} \mathrm{p}<0.001 ;{ }^{* *} \mathrm{p}<0.01 ;{ }^{*} \mathrm{p}<0.05$ (two-tailed tests).

factors were entered. Finally, we note that whether alters were blood donors, volunteers, or political activists was a robust predictor of recruitment to each respective form of civic activity.

\section{Discussion}

By introducing dyadic-level data to the mix across multiple civic outcomes, we contributed new insight into why certain people but not others are asked to get involved in civic activity. First, we find that while some relations have strong effects across all three civic activities (e.g., romantic partners), others are tailored to specific forms of civic engagement. Second, not only did the relational characteristics-interaction, shared space, homophily, and strength-have robust effects when controlling for numerous personal traits of egos and whether alters were civically active, but their inclusion rendered some of egos' traits insignificant. And third, we found that nuances in types of relations among close ties led to real differences in whether a solicitation was made; for example, while spouses were a strong source of recruitment attempts, other types of family relations had null or even negative effects on requests to be active in civic life.

Our models indicate that relational characteristics matter across the three outcomes. Further, personal traits that appeared important at the ego-level actually may be capturing relational effects. Regarding volunteer recruitment, for example, religious service attendance was a strong predictor in the individual-level only model, but its effect disappeared when including whether alters and egos were involved in the same congregation or were both religious. ${ }^{7}$ One possible explanation for this finding is that personal religiosity does not necessarily signal an interest in helping others. Rather, shared religion serves as an indicator of mutual values and interests for volunteerism, an outcome augmented by the possibility that congregations serve as mobilizing contexts providing recruitment opportunities and incentives to those involved.

In addition to showing that relational factors matter for differential recruitment, we found that their effects tended to vary from one form of civic activity to another. In fact, only the measure of tie intimacy-a spouse or other type of romantic partner-had a significant impact across all three forms. The influence of other dyadic-level characteristics on requests to get

\footnotetext{
${ }^{7}$ In auxiliary analyses, we ran a model in which only two dyadic-level factors were entered alongside the full set of ego-level variables for recruitment to do volunteer work: (1) attend the same religious congregation and (2) both religious. The coefficient for egos' religious service attendance fell to nonsignificance in this reduced level 1 model, increasing confidence that the dyadic religious measures rather than other ones explain the observed significant effect of the attendance in Model 1.
} 
Table 4

Coefficients from multilevel logistic regression models predicting recruitment to political activism.

Willingness to take political action

Model 1

Model 2

Political efficacy

$0.514^{* * *}$

$(0.084)$

$0.317^{* * *}$

Interest in politics

(0.089)

$0.326^{* * *}$

Extroversion

(0.093)

0.042

Sensation seeking

(0.085)

0.035

Physical health

$(0.064)$

Depression

-0.006
$(0.090)$

$-0.201$

Religious service attendance

(0.113)

$0.062^{*}$

$(0.031)$

Nonreligious organization participation

$0.465^{* *}$

Religious affiliation

(0.159)

0.152

$(0.260)$

Political views

0.006

$(0.053)$

Age

Female

(0.006)

$-0.280$

White

(0.152)

0.383

Black

(0.331)

$1.043^{* *}$

Latino

(0.387)

0.553

(0.391)

U.S. citizen

0.427

(0.599)

Some college education

$-0.223$

(0.186)

Four-year degree or higher

$-0.146$

(0.204)

Household income

$-0.006$

$(0.021)$

Working

$-0.042$

(0.171)

Student

Married or cohabitating

Widowed, separated, or divorced

0.332

0.116

(0.212)

0.218

(0.251)

Child 5 years old or younger in household

0.137

(0.244)

$-0.126$

Child between 6 and 12 years old in household

(0.219)

0.245

(0.211)

$-0.073$

Live in southern state

(0.157)

0.218

Live in metropolitan area

(0.196)

$0.227^{*}$

(0.104)

$0.302^{* *}$

(0.111)

0.050

$(0.118)$

0.055

$(0.107)$

0.023

(0.079)

$-0.046$

(0.113)

$-0.077$

(0.141)

0.010

(0.040)

0.386

(0.197)

0.531

(0.341)

0.003

$(0.064)$

$-0.005$

(0.008)

$-0.220$

(0.191)

0.150

(0.417)

0.770

(0.486)

0.535

(0.485)

1.132

(0.814)

$-0.490^{*}$

(0.234)

$-0.539^{*}$

(0.256)

$-0.009$

$(0.026)$

$-0.094$

(0.212)

0.237

(0.357)

$-0.197$

(0.268)

0.091

(0.311)

0.226

(0.305)

$-0.274$

(0.273)

$0.542^{*}$

(0.259)

$-0.182$

(0.197)

$-0.086$

(0.245)

Dyad-level

$0.410^{*}$

(0.192)

$1.101^{* * * *}$

(0.223)

0.167

(0.168)

0.225

(0.203)

$-0.027$

Participate together in same nonreligious organization

(0.194) 
Table 4 (continued)

\begin{tabular}{|c|c|c|}
\hline Predictor variables & Model 1 & Model 2 \\
\hline Same Sex & & $\begin{array}{c}0.448^{*} \\
(0.175)\end{array}$ \\
\hline Same race & & $\begin{array}{c}0.005 \\
(0.280)\end{array}$ \\
\hline Similar age & & $\begin{array}{c}-0.068 \\
(0.175)\end{array}$ \\
\hline Both religious & & $\begin{array}{c}0.078 \\
(0.182)\end{array}$ \\
\hline Share political views & & $\begin{array}{c}0.480^{*} \\
(0.190)\end{array}$ \\
\hline Spouse or romantic partner & & $\begin{array}{c}0.628^{*} \\
(0.249)\end{array}$ \\
\hline Parent & & $\begin{array}{c}0.581^{*} \\
(0.267)\end{array}$ \\
\hline Other family member & & $\begin{array}{l}-0.006 \\
(0.209)\end{array}$ \\
\hline Provide emotional support & & $\begin{array}{c}0.155 \\
(0.188)\end{array}$ \\
\hline Political activist & & $\begin{array}{l}4.623^{* * *} \\
(0.214)\end{array}$ \\
\hline $\begin{array}{l}\text { Alter-level } \\
\text { Constant }\end{array}$ & $\begin{array}{c}-7.674^{* * *} \\
(0.991)\end{array}$ & $\begin{array}{c}-9.820^{* * *} \\
(1.336)\end{array}$ \\
\hline AIC & 3354.179 & 2160.260 \\
\hline BIC & 3568.570 & 2478.389 \\
\hline Observations & 7449 & 7449 \\
\hline Number of groups & 1793 & 1793 \\
\hline
\end{tabular}

Note: Standard errors in parentheses.

${ }^{* * *} \mathrm{p}<0.001 ;{ }^{* *} \mathrm{p}<0.01 ;{ }^{*} \mathrm{p}<0.05$ (two-tailed tests).

involved in civic activity was unique to one or sometimes two forms. In other words, the significance of social connections for differential recruitment generally depended on the fit between a particular type of tie and the specific features of giving blood, volunteering time, and engaging in political activism. Revisiting our hypotheses in light of the empirical findings reveals the importance of this fit.

\subsection{Frequency and content of interaction}

Both frequent interaction and political discussions between dyads increased recruitment for volunteer work and political activism but not blood donation. Giving blood is generally a nonpolitical act, so we did not expect talking politics to translate into increased invitations to participate in this form of civic activity. On the other hand, volunteer work commonly addresses social problems, which are often thought to have political causes or solutions, while activism deals directly with politics. As a result, it makes sense that politically-oriented conversations provided openings for people to ask others to get involved in these forms of civic activity (Klofstad, 2007). Confirming expectations that spending more time together provides more opportunities for recruitment, we observed that monthly in-person interaction rendered alter-ego requests for volunteer work and political activism more likely. Contrary to our hypothesis, however, frequent interaction did not significantly influence solicitations for blood donation. It is possible that this null finding reflects the fact that blood can only be given roughly 6 times a year (every 56 days), limiting the frequency of donation. Volunteer work and political activism do not have such participatory restrictions.

\subsection{Shared space}

Shared space between alters and egos increased the likelihood of recruitment to give blood and to do volunteer work. People living in the same community or attending the same religious congregation made more requests of each other to donate blood than those not sharing these contexts. Given that these findings were net of interaction and other relational characteristics, they likely reflect spatial opportunities-such as locally-based donation centers or mobile blood drives stationed at congregations-common to alter-ego pairs, which make giving easier and more convenient.

Joint religious organizational participation was also important for volunteer recruitment as was co-involvement in another type of voluntary association. Institutions of civil society regularly host social service programs and tend to be sources of mutual interests and identities. Thus, civic spaces provide opportunities for engagement and capitalize on common values, which presumably explains why, beyond other relational characteristics that bring people together (like frequency of interaction), overlapping memberships in religious and non-religious groups boosted solicitations to do volunteer work. 
Interestingly, these shared contexts did not significantly affect recruitment to political activism. Given variation in the extent to which voluntary organizations are politicized (Beyerlein and Chaves, 2003; Verba et al., 1995), this finding may reflect measurement issues in that all types of groups were lumped together. Had we been able to capture joint participation in voluntary organizations with an explicitly political bent, perhaps the measure of shared associational membership would have significantly distinguished activist recruits from non-recruits.

\subsection{Homophily}

The results for the various homophily measures were mixed. As posited, dyads matched on sex were more susceptible to recruitment attempts for volunteer work and political activism, suggesting that differences in gender roles and expectations persist in these forms of civic activity. Shared religiousness was also significant for volunteering. Not surprisingly, political agreement between dyads played an important role in recruitment to the politicized and often controversial civic form of activism. People on opposite ends of the political spectrum may occasionally find common ground on issues, making recruitment an option. But our results indicate that such situations are rare. Individuals are much more likely to turn to likeminded peers when seeking to get others involved in political action.

Relative to being recruited for the two other forms of civic activity, homophily mattered little for soliciting blood. This is not surprising as blood donation focuses on the general cause of saving strangers' lives, making it less sensitive to political cleavages and consequently less dependent on shared political views for recruitment. Moreover, blood donation is a solitary act that follows a specific protocol (e.g., trained staff extract blood), and thus is not subject to sex stratification in terms of duties and tasks, rendering it less susceptible to same-sex recruitment. The one significant effect we did find for homophily was negative-dyads matched on race were less likely to ask each other to give blood. Thus, unlike volunteer work and political activism, it appears that homophilous social relations are generally inconsequential for recruiting blood donors, with racial homophily actually hindering such recruitment.

\subsection{Tie strength}

Intimate close ties in the form of marriage and other romantic partnerships increased the likelihood of recruitment for all three forms of civic activity. This was the only relational characteristic to have such an influence. While this was expected, intimate connections were also posited to have stronger effects for recruitment for volunteer work and political activism since these activities tend to entail greater opportunities to enhance valued relationships and to involve more challenging and daunting experiences. But the magnitude of the intimate-tie effect was also sizable for blood donation. Thus, we underestimated the recruitment effect of romantic partners for this form of civic activity, who indeed play an important role, perhaps helping to overcome fears associated with needles, pain, or fatigue.

Regarding other dimensions of tie strength, the parent-child bond had a significant effect on recruitment to political activism while an emotionally-supportive connection was important for soliciting for volunteer work. Given that political action is often contentious, including confronting authorities or counterdemonstrators, parents may see its intensity as a way to revitalize the relationship they have with their children or enhance an already robust connection. Furthermore, parents may know their children particularly well and be able to infer whether their child will be insulted or excited by the cause and/ or tactics for which they are recruiting, or whether the child might benefit from the engagement. Because volunteer work may involve working with vulnerable populations, engaging in it could stir up strong reactions, making emotional ties particularly attractive for recruitment to this form of civic activity. Somewhat surprisingly, we observed that other types of family ties (those not romantic or parental in nature) had a null effect on recruitment to give blood and take political action and a significant negative effect for volunteer requests. One possibility is that since people are recruiting their spouses and nonmarried romantic partners to all three types of civic activity, they are seeking couple-oriented time that excludes other types of family members, such as siblings, cousins, aunts, or uncles.

This highlights the importance of paying attention to gradations in tie strength. Even among close ties collected through ego-centric data, differences in intimacy, emotional support, and type of familial connections matter for explaining differential recruitment to civic activity. Thus, while many studies focus on the strong-weak tie divide, we contribute to the literature by showing that even among close ties there are real differences in how varied relationships translate into civic solicitations.

\section{Conclusion}

Broadly speaking, our study demonstrates the power of social connections for understanding variation in requests to get involved in civic life. More specifically, it reveals that certain types of relations have a greater or weaker influence on recruitment depending on the form civic activity takes. Invitations are most likely to be extended when the content of people's close ties relate in meaningful ways to the specific dynamics involved in donating blood, volunteering time, and engaging in political activism. This provides new insight into the puzzle of why recruitment attempts are made between some people but not others.

Our paper motivates a number of directions for future research. We focused on the most rudimentary aspect of recruitment: the presence or absence of a recruitment attempt. In many ways this is an asset given that all other stages follow from 
it. A natural extension of our work would be to apply a dyadic perspective to different stages of the recruitment process, such as whether people assent to a request to get involved (Brady et al., 1999; Lim, 2008). There is also the issue of how social connections affect the spread of recruitment (Walgrave and Wouters, 2014). Future studies could adopt a dyadic approach similar to ours and investigate how alter-ego relations, such as quality and content of interaction, dimensions of value homophily, and levels of intimacy, affect whether an invitation to be civically active is accepted, rejected, or passed on. Based on our study, the impact of these relations on different phases of recruitment are likely to vary from one form of civic activity to another.

Like many studies using surveys to collect network data, we only had access to a limited number of ego's alters (up to five of their closest ties). Although significant variation in solicitation attempts was observed between egos and alters, future research on differential recruitment should cast a wider net and capture a greater number and diversity of social ties, including those of a weaker variety. In regard to our outcome variables, we focused on solicitations to three broad civic activities-blood donation, volunteer work, and political activism. But there is considerable variation in the types of actions and causes subsumed under the rubrics of volunteer work and political activism. Another avenue for future study, then, is to assess how dyadic characteristics influence recruitment to more specific causes, duties, or tasks of volunteer work and political activism. The classic distinction between high-cost/risk and low-cost/risk social action (McAdam, 1986) is one such possibility for doing so. Introducing more detailed categories of civic activity could nuance what types of social connections are most important for understanding differential recruitment.

At the same time, our study makes a contribution in the breadth of its focus. Typically, studies focus only on a single form of civic activity, such as political activism (but see Lee et al., 1999), and thus we do not know whether factors relevant to explaining one form are also relevant for others. Focusing on a range of forms and comparing and contrasting across them broadens our understanding of the processes associated with civic engagement. For example, volunteer work and political activism share common dyadic characteristics that encourage recruitment, like frequent interaction, political discussions, sex homophily, and intimacy. But they are also uniquely influenced by specific recruitment factors, with shared organizational affiliations mattering more for volunteer work and political agreement mattering more for activism. That different relational aspects of ties become more or less salient depending on the civic activity is relevant for network analysis more broadly. Network models are used to understand recruitment phenomena as divergent as terrorism to working at a bank. The idea that relational factors matter for recruitment, and matter differently depending on the nature of the activity, can be exported to a range of studies.

By examining nuances in close ties, our study also advances knowledge about solicitation attempts among social connections that are most influential. Not all close ties are equally likely to generate requests to be civically active. Rather, whether these ties are sources of recruitment depends on gradations in tie strength and intimacy as well as other relational differences. But, most importantly, we demonstrate that it is not enough to simply focus on the recruit or the recruiter to understand solicitations to civic activity: relationships matter. Only by looking at what is shared between the two parties can we gain a full portrait of the groundwork in which solicitations take root.

Finally, our study has practical implications. Everyday non-profit staffs, social service coordinators, and grassroots organizers are charged with the difficult task of enlisting participants for civic activity. Like scholars, they are well aware of the benefits of "asking," as evidenced by their myriad recruitment campaigns. The problem, however, is that not everyone is equally likely to be asked. The perspective of "rational prospecting," in which people perceived to be the most effective participants are disproportionally targeted, privileges individual attributes and does little to help us understand how to diversify the pool of potential participants since the same kinds of people are asked over and over again. But our results show that there is more to differential recruitment. Looking at how relational characteristics affect recruitment processes carries with it possibilities for ways to integrate groups that have been historically marginalized in civic life. For instance, awareness about biases toward homophily, and strategic efforts to diverge from such tendencies, could help bring in new, more diverse cohorts of participants. By focusing on the social basis of differential recruitment, groups of people who have remained on the sidelines because they have never been asked to get involved may be mobilized into action, creating a more balanced, and thus stronger, civil society.

\section{References}

Beyerlein, Kraig, Chaves, Mark, 2003. The political activities of religious congregations in the United States. J. Sci. Study Relig. 42, $229-246$.

Brady, Henry E., Lehman Schlozman, Kay, Verba, Sidney, 1999. Prospecting for participants: rational expectations and the recruitment of political activists. Am. Political Sci. Rev. 93, 153-168.

Bryant, W. Keith, Jeon-Slaughter, Haekyung, Tax, Aaron, 2003. Participation in philanthropic activities: donating money and time. J. Consumer Policy 26, $43-73$.

Callegaro, Mario, Disogra, Charles, 2008. Computing response metrics for online panels. Public Opin. Q. 72, 1008-1032.

Chang, Linchiat, Krosnick, Jon A., 2009. National surveys via RDD telephone interviewing versus the internet: comparing sample representativeness and response quality. Public Opin. Q. 73, 641-678.

Dennis, J. Michael, 2010. Summary of KnowledgePanel Design. GfK, Palo Alto, CA.

Drake, Alvin W., Finkelstein, Stan N., Sapolsky, Harvey M., 1982. The American Blood Supply. MIT Press, Cambridge, MA.

Einwohner, Rachel L., 1999. Gender, class, and social movement outcomes: identity and effectiveness in two animal rights campaigns. Gend. Soc. 13, 56-76.

Feld, Scott L., 1981. The focused organization of social ties. Am. J. Sociol. 86, 1015-1035.

Gould, Roger V., 2003. Why do networks matter? Rationalist and structuralist interpretations. In: Diani, M., McAdam, D. (Eds.), Social Movements and Networks. Oxford University Press, New York, pp. 233-257.

Groves, Robert, 2006. Nonresponse rates and nonresponse bias in household surveys. Public Opin. Q. 70, 646-675. 
Groves, Robert, Peytcheva, 2008. The Impact of nonresponse rates on nonresponse bias: a meta analysis. Public Opin. Q. 72, 167-189.

Huckfeldt, Robert, Sprague, John, 1995. Citizens, Politics, and Social Communication. Cambridge University Press, Cambridge.

Jasper, James M., 1997. The Art of Moral Protest. University of Chicago Press, Chicago.

Klofstad, Casey A., 2007. Talk leads to recruitment. Political Res. Q. 60, 180-191.

Knoke, David, 1990. Networks of political action: toward theory construction. Soc. Forces 68, 1041-1063.

Kuumba, Bahati M., 2001. Gender and Social Movements. AltaMira Press, Walnut Creek, CA.

Lazarsfeld, Paul F., Merton, Robert K., 1954. Friendship as a social process: a substantive and methodological analysis. In: Berger, M.A. (Ed.), Freedom and Control in Modern Society. Van Nostrand, New York, pp. 18-66.

Lee, Lichang, Piliavin, Jane A., Call, Vaughn R.A., 1999. Giving time, money, and blood: similarities and differences. Soc. Psychol. Q. 62, 276-290.

Lim, Chaeyoon, 2008. Social networks and political participation: how do networks matter? Soc. Forces 87, $961-982$.

Luken, Verónica de Miguel, Tranmer, Mark, 2010. Personal support networks of immigrants to Spain: a multilevel analysis. Soc. Netw. 32, 253-262.

McAdam, Doug, 1986. Recruitment to High-risk activism: the case of freedom summer. Am. J. Sociol. 92, 64-90.

McAdam, Doug, 1992. Gender as a mediator of the activist experience: the case of freedom summer. Am. J. Sociol. 97, 1211-1240.

McAdam, Doug, Paulsen, Ronnelle, 1993. Specifying the relationship between social ties and activism. Am. J. Sociol. 99, 640-667.

McPherson, Miller J., Smith-Lovin, Lynn, 1987. Homophily in voluntary organizations: status distance and the composition of face to face groups. Am. Sociol. Rev. 52, 370-379.

McPherson, Miller J., Smith-Lovin, Lynn, Cook, James M., 2001. Birds of a feather: homophily in social networks. Annu. Rev. Sociol. $27,415-444$.

Musick, Marc, Wilson, John, 2008. Volunteers: a Social Profile. Indiana University Press, Bloomington, IN.

Musick, Marc, Wilson, John, Bynum, William B., 2000. Race and formal volunteering: the differential effects of class and religion. Soc. Forces 78, $1539-1571$.

Olzak, Susan, 1983. Contemporary ethnic mobilization. Annu. Rev. Sociol. 9, 355-374.

Paik, Anthony, Navarre-Jackson, Layana, 2011. Social Networks, recruitment, and volunteering: are social capital effects conditional on recruitment? Nonprofit Voluntary Sect. Q. 40, 476-496.

Pallares, Amalia, Flores-González, Nilda, 2010. Introduction. In: Pallares, A., Flores-González, N. (Eds.), ¡Marcha! : Latino Chicago and the Immigrant Rights Movement. University of Illinois Press, Urbana. Pp. xv-xxix.

Rotolo, Thomas, Wilson, John, 2006. Substitute or complement? Spousal influence on volunteering. J. Marriage Fam. 68, 305 -319.

Sampson, Robert J., McAdam, Doug, MacIndoe, Heather, Weffer-Elizondo, Simon, 2005. Civil society reconsidered: the durable nature of community organizational context of collective civic action. Am. J. Sociol. 111, 673-714.

Schussman, Alan, Soule, Sarah A., 2005. Process and protest: accounting for individual protest participation. Soc. Forces $84,1083-1108$.

Snow, David A., Zurcher, Louis A., Ekland-Olson, Sheldon, 1980. Social networks and social movements: a microstructural approach to differential recruitment. Am. Sociol. Rev. 45, 787-801.

Sojka, Birgitta Nilsson, Sojka, P., 2008. The blood donation experience: self-reported motives and obstacles for donating blood. Vox Sang. 94, 56-63.

Soule, Sarah A., 1997. The Student divestment movement in the United States and tactical diffusion: the Shantytown protest. Soc. Forces 75, 855-882.

Stoll, Michael A., 2001. Race, neighborhood poverty, and participation in voluntary associations. Sociol. Forum 16, $529-557$.

van Duijn, Marijtje A.J., van Busschbach, Jooske T., Snijders, Tom A.B., 1999. Multilevel analysis of personal networks as dependent variables. Soc. Netw. 21, 187-209.

Verba, Sidney, Lehman Schlozman, Kay, Brady, Henry E., 1995. Voice and Equality. Harvard University Press, Cambridge, MA.

Walgrave, Stefann, Wouters, Ruud, 2014. The missing link in the diffusion of protest: asking others. Am. J. Sociol. 119, 1670-1709.

Wellman, Barry, 1979. The community question: the intimate networks of East Yorkers. Am. J. Sociol. 84, $1201-1231$.

Wellman, Barry, 1992. Which types of ties and networks provide what kinds of social support. Adv. Group Process. 9, $207-235$.

Wilson, John, 2000. Volunteering. Annu. Rev. Sociol. 26, 215-240.

Yeager, David S., Krosnick, Jon A., Chang, Linchiat, Javitz, Harold S., Levendusky, Matthew S., Simpser, Alberto, Wang, Rui, 2011. Comparing the accuracy of RDD telephone surveys and internet surveys conducted with probability and non-probability samples. Public Opin. Q. 75, $709-747$. 